\title{
Arbor
}

\section{Hispanismo que viene: Israel y Marruecos}

\section{Ruth Fine}

Arbor CLXVIII, 664 (Abril 2001), 481-492 pp.

Al asumir el desafío propuesto por la revista Arbor y abocarme a buscar, reunir y ordenar datos sobre los estudios hispánicos en la zona geográfica donde resido - Medio Oriente- sabía que estaba aceptando una tarea compleja y, probablemente, no realizable de modo acabado. No me equivocaba. Las dificultades han sido múltiples y, principalmente, suscitadas por el conflicto político y aun bélico en el que nos encontramos sumidos. Debido al hecho de que mi epicentro académico y existencial se encuentra en Israel, la comunicación con las universidades de los países con los que estamos en conflicto se ha hecho i mposible (me refiero, entre otros, al Líbano, Siria, Irak, etc.). Lamentablemente, tampoco los países vecinos con los que Israel mantiene una relación pacífica me han dado un fácil acceso a la necesaria información respecto del estado de los estudios hispánicos en sus centros académicos. Ello ha sido especialmente notorio en lo que respecta a Egipto, de donde aún no he podido obtener respuestas concretas. En relación con Jordania, mi tarea fue menos ardua, pero los datos obtenidos son insuficientes para escribir un apartado en relación con dicho país. Tengo la certeza de que con más tiempo, perseverancia y contactos apropiados, además de un clima político más favorable - el que todos ansiamos- este panorama del hispanismo en Medio Oriente podrá ser completado de modo adecuado. Es ésta la razón por la que sólo me atrevo a presentar un informe exhaustivo respecto de Israel y otro, parcial, acerca de Marrruecos, país con el cual he podido contactarme a través de algunos de sus destacatos estudiosos, a quienes he tenido el agrado de conocer en un Coloquio en Israel, organizado por la universidad de Haifa, en febrero de este año. 


\section{Israel}

Los estudios hispánicos en este país son vastos y diversos. Dada tal amplitud me he visto en la necesidad de aplicar un criterio selectivo y ordenador, de acuerdo con el cual he decidido obviar los estudios hispanoamericanos, los que ocupan un lugar de mucha importancia en Israel, principalmente en la Universidad Hebrea de Jerusalén (literatura, historia y estudios sociales de Iberoamérica) y en la Universidad de Tel Aviv (historia iberoamericana). Me centraré, entonces, en las áreas del hispanismo que comprendan los estudios relativos a la literatura española y al judeo-español.

\subsection{Literatura y lengua}

\subsubsection{Universidad Hebrea de Jerusalén}

La lengua española y su literatura figuraron desde una etapa muy temprana entre los estudios de la Universidad Hebrea de Jerusalén. No obstante, sólo en 1967 fue creado el Departamento de Estudios Españoles y Latinoamericanos, en el que se reunieron cursos dictados previamente en diversas secciones de las facultades de Humanidades y Ciencias Sociales, sobre lengua, literatura, historia, política, sociedad y cultura española e hispanoamericana.

El Departamento está constituido por dos secciones: una sección literaria y una sección histórico-social, las cuales proporcionan un marco interdisciplinario de enseñanza e investigación (en los tres niveles: B.A., M.A. y Doctorado), y de preparación de especialistas en las respectivas áreas. En su sección literaria, el Departamento de Estudios Españoles se ocupa fundamentalmente del análisis de los tres géneros literarios -lírica, narrativa y drama - durante la Edad Media, el Siglo de Oro y la época moderna y contemporánea, con especial atención a las áreas de poética, semiótica y lingüística. Como parte de esta sección, se ofrece a los alumnos que no son hispano-parlantes, un programa especial con cursos introductorios de literatura española e hispanoamericana en hebreo, y cursos intensivos en castellano. Es importante destacar el dramático incremento que se registra en los últimos años de estudiantes no hispanoparlantes deseosos de acercarse a los estudios iberoamericanos, lo cual intensifica el desarrollo de un sólido plan de estudios de la lengua española.

A partir del año 1992, el Departamento publica anualmente la revista Reflejos, que da expresión a la investigación académica en sus dos áre- 
as de especialización: literatura e historia. En sus páginas aparecen trabajos de investigadores del Departamento y de otros centros académicos, cuyos temas de investigación conciernen a Iberoamérica.

El Departamento de Estudios Españoles se beneficia anualmente con la visita de profesores y de representantes expertos en el área del hispanismo. Mediante su seminario Departamental, se brinda un foro propicio para la presentación de especialistas de Israel y del extranjero en materias concernientes a Iberoamérica, cumpliendo, mediante estas conferencias, con una importante función de divulgación de la investigación que se proyecta a la comunidad hispano-hablante en Israel. Entre otros, el presente año han dictado conferencias el Prof. F. Márquez Villanueva (Harvard University) y el Prof. T. Mermall (CUNY), quienes han hablado sobre Cervantes y sobre Ortega y Gasset, respectivamente.

Periódicamente se realizan coloquios y congresos. Así el «Coloquio del '98», fue llevado a cabo en torno a la temática del aniversario de dicha generación y del año lorqueano. Asimismo, el Departamento cuenta con un programa de intercambio de profesores con la Universidad Complutense de Madrid, por el cual anualmente se recibe la visita de un profesor que dicta un curso de literatura o historia española.

En el campo de la literatura española, los investigadores del Departamento son la Dra. Sofia Kantor y la que escribe este informe, la Dra. Ruth Fine. La primera es una especialista en Literatura Medioeval, quien ha publicado estudios sobre los trovadores, El Cid, El libro del Buen Amor, Berceo y El libro de Sindibad, adoptando, en muchos de estos trabajos, una perspectiva general semántica. Así, por ejemplo, en relación con El libro de Sindibad, ha trabajado sobre las variaciones en torno al eje temático «engaño-error». Actualmente, la Dra. Kantor está realizando una investigación acerca de la alegoría, especialmente centrada en Los Milagros de Berceo y en El libro del Buen Amor. Respecto de este último texto, su trabajo se ocupa del campo semántico «daño y engaño», en el marco de la diatriba contra Don Amor.

En cuanto a mi investigación personal, ésta se centra en el Siglo de Oro de la literatura española, y más específicamente en los estudios cervantinos. Me encuentro completando un estudio semiótico-narratológico abarcador sobre $E l$ Quijote, algunos de cuyos capítulos ya han aparecido como artículos, incluyendo perspectivas de índole comparativa (así, un paralelo entre la concepción estética de Cervantes y Borges, como también la influencia del Quijote en la generación del '98). Asimismo, estoy llevando acabo un trabajo conjunto con un especialista en Biblia - el Dr. Menajem Argov - acerca de la presencia del Antiguo Testamento en El Quijote. Por último, he dictado el presente año lectivo un seminario sobre 
lo hebreo, lo judío y lo converso en la obra de Cervantes, lo cual me ha introducido en este campo de investigación, cuyos primeros resultados espero publicar en poco tiempo. En este mismo campo me encuentro dirigiendo la tesina de una alumna de maestría. En el marco de la literatura española contemporánea dirijo también otra tesina que se ocupa del microrrelato en la literatura española actual, con énfasis en los aspectos narratológicos del relato brevísimo.

En el marco de otros Departamentos de la Universidad Hebrea se desarrollan también estudios relativos al hispanismo. Así, el Dr. John London, del Departamento de Filología Románica, es un investigador del teatro español. Ha publicado ya diversos estudios sobre los manuscritos de las obras dramáticas de Federico García Lorca, sobre la recepción del teatro español de la posguerra, sobre el teatro catalán contemporáneo, así como también ha escrito trabajos acerca de Ruiz de Alarcón, sobre la traducción del teatro español al inglés y en torno a la escenografía española del siglo XX. Actualmente se encuentra desarrollando una investigación sobre la recepción de la literatura del Siglo de Oro en Alemania, durante el período del Tercer Reich.

El Departamento de Teatro cuenta también con la presencia de un especialista en el teatro del Siglo de Oro: el Dr. Isaac Benabú. Las publicaciones de este investigador son numerosísimas, así como también la dirección y producción de obras teatrales de ese período y del teatro lorqueano, tanto en Israel (en hebreo) como en el exterior. Me importa destacar su presente campo de investigación, que se centra en dos direcciones. La primera de ellas corresponde a la problemática de la representación en el teatro del Siglo de Oro, en cuyo marco aspira reestablecer la diferenciación entre la estética literaria y la teatral, acercándose al texto dramático como a un «manual de representación» y no como a un texto para ser leído en soledad. En este sentido, se pone especial énfasis en el caso de la comedia española del siglo XVII, a partir de la cual se pretende aplicar los resultados de la investigación, en colaboración con estudiosos y compañías teatrales de todo el mundo. Otro de los objetivos primordiales de esta investigación consiste en situar a la comedia española en el marco del teatro del Renacimiento europeo.

Un segundo campo de investigación desarrollado por el Dr. Benabú trata la kharja - la serie hebreo-romance-como un punto de encuentro entre tres tradiciones literarias: la árabe, la latina y la hebrea. El estudio pretende iluminar cuestiones de paleografía, así como la identidad lingüística, poética y prosódica de la kharja, en el marco de su muwashashah. 


\section{Hispanismo que viene: Israel y Marruecos}

\subsubsection{Universidad Ben Gurión del Neguev}

En esta joven universidad, situada en la ciudad de Beer Sheva, en el marco del Departamento de Literatura Hebrea, trabaja un profesor e investigador - el Dr. Luis Landau-, quien se ha abocado a estudios comparativos relacionados con la obra cervantina. Sus publicaciones comprenden artículos que tratan la influencia de Cervantes en la literatura hebrea, así como también estudios acerca del interés de Freud por la obra cervantina y por el español, donde se analizan puntos de contacto y diferencias cardinales entre Cervantes y Freud. El Dr. Landau dicta también cursos para estudiantes avanzados donde analiza la metamorfosis del Quijote y del género picaresco en la literatura hebrea contemporánea. Asimismo, dicho investigador desarrolla un abarcador estudio sobre Cervantes y el judaísmo, el cual está en vías de publicación. Vale la pena mencionar que el Dr. Landau, conjuntamente con su esposa, Beatriz Landau, han sido los responsables de la última y excelente traducción del Quijote al hebreo.

\subsubsection{Universidad de Bar-Ilán}

En la presente universidad se encuentra la investigadora y profesora Ruth Reichelberg, quien es catedrática del Departamento de Literatura Comparada. Sus trabajos en el campo del hispanismo contemplan la relación del Quijote con la tradición judía, considerando la obra maestra cervantina como un texto que podría ser fruto de la pluma de un marrano. La presente investigadora ha publicado artículos varios sobre la obra de Cervantes, focalizando en muchos de ellos el sentido de los antropónimos y de los números en dicha obra, desde una perspectiva judía y cabalística. También ha estudiado comparativamente la pertenencia de Calderón y Claudel al Barroco. Sus trabajos presentes consisten en una traducción de obras de Jorge Guillén al francés, así como también un estudio abarcador sobre los contactos lingüísticos y conceptuales entre ciertas obras del Siglo de Oro español y textos judíos diversos. La Prof. Reichelberg dicta cursos de carácter comparativo, en los que trata la obra cervantina y sus puntos de contacto con otros autores, como J. L. Borges.

El Departamento de Literatura Comparada ha organizado en el mes de octubre del año 1998, un Coloquio en honor al centenario de F. G. Lorca, en el que participaron investigadores de otras universidades de Israel y del exterior. 


\subsubsection{Universidad de Haifa}

La presente universidad ha inaugurado en el año 1998, en el marco del Departamento de Hebreo y de Literatura Comparada, una Unidad de Investigación de las Culturas de España, fundada y dirigida por la Profesora Aviva Dorón. Esta unidad tiene como objetivo el estudio y la investigación de las culturas de España, en un amplio espectro de disciplinas, tales como la literatura, la filosofía, la historia, la sociología, la psicología, etc. Con este fin, se promueve la cooperación entre investigadores de España, Israel y otros países de Medio Oriente, y se organizan seminarios y coloquios en Israel y en otros países. El primero de estos encuentros fue organizado por la Prof. Dorón en Toledo y se denominó «El encuentro de las tres culturas». El último Coloquio fue realizado en Haifa, en febrero del corriente año, auspiciado por las universidades de Haifa, la Universidad Autónoma de Barcelona, la Universidad de Alcalá y la Universidad Mohammed V, de Rabat. El Coloquio contó con la presencia de investigadores de distintas universidades de Israel, España, Marruecos, Egipto y Jordania. En un contexto interdisciplinario - con especial atención al área literaria - se trataron las relaciones interculturales en el ámbito de la España medieval. Entre los resultados del Coloquio se conformó un grupo de investigación que continuará desarrollando el diálogo interdisciplinario entre los estudiosos de Israel y de los países árabes por intermedio del nexo español. Estos coloquios proseguirán realizándose periódicamente (otoño del 2000 en Barcelona y otoño del 2001 en Rabat), y cuentan con el apoyo de la Unesco.

La Prof. Aviva Dorón, es una estudiosa de Literatura Medieval, quien ha abierto una nueva línea de investigación, centrada en las relaciones de la poesía hispanohebrea y la literatura de la España cristiana. En sus numerosos trabajos, ha presentado las innovaciones poéticas de dicha literatura, relacionándolas con las corrientes literarias españolas y mostrando que, aunque se conservara los modelos y la métrica andalusíes, la lírica hispanohebrea desarrolló características poéticas similares a la de la poesía española de aquel período.

La Prof. Dorón ha publicado estudios sobre Yehudá ha-Leví, Todros ha-Leví Abulafia, Abraham Ibn Ezra, Shlomo Ibn Gabirol y otros poetas hispanohebreos, especialmente aquéllos que escribieron en la Toledo de Alfonso X. En la actualidad su investigación se centra en la literatura hebrea de la España cristiana, que floreció en los centros culturales de Castilla, Aragón y Cataluña, desde la segunda mitad del siglo XII hasta fines del siglo XV. 


\subsubsection{Escuela Lewinski de Educación Superior}

En esta institución académica se encuentra el Centro Interuniversitario de Estudios Hispano-judíos, dirigido por la Prof. Aviva Dorón, donde se otorgan títulos de maestría en el área hispano-judía, con especial énfasis en la literatura hispanohebrea medioeval.

\subsection{El judeo-español: su lengua y literatura}

El desarrollo de los estudios relativos a la lengua y literatura judeo-españolas han alcanzado un creciente ímpetu en los últimos años en nuestro país. Las principales universidades cuentan con cursos, cátedras y centros de investigación abocados a este campo y, periódicamente, se realizan coloquios y congresos en torno a temas concernientes al ladino. En el último de ellos - efectuado en Jerusalén durante el corriente año- se ha tratado la problemática en torno a la escritura de esta lengua. Asimismo, hay numerosas actividades no académicas (programas radiales, un periódico en judeo-español - Aki Yerushalayim -, concursos de creación literaria, cursos parauniversitarios, conciertos de música y canciones en ladino, etc.), en muchos casos, conectadas o patrocinadas por las universidades.

\subsubsection{La Autoridad Nacional para el ladino y su cultura}

La presente institución fue fundada como resultado de una ley parlamentaria del año 1996, con el objeto de ampliar el conocimiento de la cultura judeo-española en todas sus manifestaciones y desarrollar la investigación y la enseñanza de dicha cultura. Entre sus metas también se encuentra la de documentar y catalogar los tesoros culturales de la lengua judeo-española. Así, ya han sido catalogados unos 2000 libros en el marco del proyecto bibliográfico — el primero en su índole — de la Biblioteca Nacional. También se ha iniciado la redacción de un diccionario hebreo-ladino y ladino-hebreo.

La presente institución ha supervisado, asimismo, la distribución de cincuenta becas para estudiantes, en las carreras de lengua y literatura judeo-españolas de las distintas universidades del país.

\subsubsection{Universidad Hebrea de Jerusalén}

En esta universidad, en el marco del Departamento de Lengua Hebrea, existe una Unidad de Lenguas Judías, la cual incluye estudios del ladino 
y de su literatura en los tres niveles: B.A., maestría y doctorado. Además de la adquisición y del estudio de la lengua (nivel de principiantes y de avanzados), los cursos dictados actualmente en esta sección comprenden perspectivas comparativas entre el ladino y otras lenguas romances, el análisis de su estructura, la especificidad del dialecto ladino hablado en la zona de los Balcanes y de la literatura desarrollada a partir de él.

El director de la sección correspondiente al judeo-español es el investigador y profesor David Bunis, quien ha publicado ya diversos trabajos sobre el desarrollo del dialecto judeo-español de los Balcanes, entre los siglos XVI y XX, en función de los testimonios literarios existentes. El profesor Bunis ha estudiado también el judeo-español del norte de África. En la actualidad, se encuentra desarrollando un trabajo de índole lingüística, literararia e histórica, que revisará el desarrollo del ladino a partir de su contacto con otras lenguas, especialmente con el turco.

En el marco de la sección de ladino del Departamento de Lengua Hebrea, están en vías de realización dos trabajos de doctorado. El primero de ellos trata aspectos dialectológicos del ladino, en tanto que el segundo consiste en un estudio de determinados aspectos del folklore y de la literatura en dicha lengua.

Cabe mencionar que el Dr. Isaac Benabú, del Departamento de Teatro de esta universidad - ya nombrado anteriormente en relación con sus investigaciones en teatro del Siglo de Oro- ha publicado diversos trabajos sobre los orígenes y la evolución del ladino.

La universidad Hebrea cuenta, también, con el Centro de Investigación y Estudio de la Herencia Sefardí y Oriental -Misgav Yerushalayim - ubicado en la Facultad de Humanidades. Este Centro ofrece un amplio espectro de cursos para estudiantes de B.A. y maestría. Se trata de un centro de carácter multidisciplinario (literatura, historia, lingüística, folclor, filosofía, etc.), lo cual se refleja en sus cursos, investigaciones y, especialmente, en sus numerosas publicaciones. Asimismo, el centro organiza coloquios y congresos internacionales que se realizan cuatrienalmente y cuyas actas son publicadas después. El próximo congreso se efectuará en junio del presente año y versará sobre las lenguas y literaturas de los judíos sefardíes y orientales, con un énfasis especial en el ladino y su literatura.

\subsubsection{Universidad Ben Gurión del Neguev}

En esta universidad, como parte del Departamento de Literatura Hebrea, trabaja un grupo de investigadores que se ocupa de diferentes as- 
pectos de la lengua judeo-española y de su literatura, y ello en el marco de la Cátedra de Folklore Judeo-Sefardí -Estelle S. Frankfurter-, fundada en el año 1998, cuyo objetivo es promover y desarrollar los estudios sefardíes (proyectos de investigación, publicaciones académicas, enseñanza, congresos, etc.). La directora de esta cátedra es la Profesora Tamar Alexánder, cuyo campo de especialización es el del relato folklórico, dentro del cual se centra primordialmente en la tradición del cuento popular en ladino. En este área la profesora Alexánder ha publicado ya numerosos trabajos, que abarcan, entre otros, el estudio de los proverbios, leyendas y cuentos morales en judeo-español, como así también las relaciones intertextuales entre probables fuentes judías y los relatos judeoespañoles. De reciente publicación es el trabajo acerca de la narración tradicional sefardí, en el cual reúne los hallazgos de la amplia investigación realizada en estos últimos años en torno a la literatura folklórica judeo-española.

Otro de los investigadores de la Cátedra de Estudios Sefardíes es el Prof. Jacob Bentolila, de los pocos especialistas en el mundo en hakitía, el dialecto judeo-español de Marruecos. Entre sus trabajos, se destacan los realizados junto con la Prof. Alexánder: el sentido de los nombres propios en los proverbios en dialecto hakitía, los elementos hispánicos en los refranes judeo-españoles de Marruecos y las relaciones intertextuales entre los proverbios hispánicos y los proverbios en hakitía. Ambos han realizado, también, un proyecto que se encuentra ya en vías de finalización, consistente en la publicación y el análisis de trescientos proverbios hallados en un manuscrito donado por una familia sefardí que lo tenía en su poder.

Matilda Koen-Sarano, docente de ladino en la Cátedra mencionada, se halla abocada a una ambiciosa empresa de recopilación, edición y traducción de relatos judeo-españoles de todo el mundo. En el marco de este proyecto se han publicado ya varios tomos, el último de los cuales está por aparecer, los cuales incluyen centenares de relatos pertenecientes a esta tradición, base fundamental para investigaciones futuras en el campo.

El Dr. Luis Landau (ya mencionado más arriba en relación con su investigación en literatura española), es también parte del plantel de estudiosos de esta Cátedra. Sus trabajos al respecto han consistido en el estudio de la creación de carácter religioso más importante en ladino: $M e^{\prime} a m L o ' e z$, y ello desde una perspectiva literaria, que constata la utilización de fuentes literarias y del Midrash en dicha obra. Asimismo, el Dr. Landau ha publicado artículos acerca del romance judeo-español. 
La cátedra de Estudios Sefardíes cuenta con unos ochenta estudiantes, a los que se les ofrece tanto el estudio de la lengua judeo-española como cursos relativos a su literatura (así, el desarrollo de los proverbios en esa lengua, dictado por la Prof. Alexander para estudiantes de maestría). En vías de realización se encuentra una tesina de maestría, centrada en el concepto de «judío» en los proverbios judeo-españoles y su comparación con los proverbios españoles, como también una tesis de doctorado relativa a las coplas de Yosef: la obra más importante de poesía sefardí de tradición oral.

\subsubsection{Universidad de Bar-Ilán}

Esta universidad cuenta también, dentro de su Departamento de Literatura del Pueblo Judío, con una Sección de Estudios Sefardíes, cuyo director es el Dr. Shmuel Rafael. La presente Sección fue fundada en el año 1985 y ha sido pionera en la enseñanza de la lengua judeo-española, a través de la publicación de los dos primeros textos de estudio de dicha lengua en Israel, para principiantes y avanzados. La Sección de Estudios Sefardíes cuenta con unos ochenta estudiantes y su perspectiva es interdisciplinaria.

El Dr. Rafael es especialista en literatura judeo-española, quien ha publicado ya numerosos trabajos relativos al romance en ladino. Actualmente se encuentra trabajando en la investigación de la literatura del Holocausto en ladino. Otros miembros del plantel de profesores e investigadores de esta sección son la Prof. Ora Schwarzwald —dedicada a aspectos lingüísticos del judeo-español-y el Prof. Moshé Orfali, historiador.

En el marco de la presente Sección se enseña el ladino en sus dos niveles, se dictan cursos de literatura, historia, música y se organizan coloquios sobre diferentes aspectos de la cultura judeo-española. El último coloquio se realizó en abril de este año y trató el tema de los judíos sefardíes durante el Holocausto. Asimismo, cada seis meses se realizan jornadas denominadas «maratónicas», durante las cuales investigadores, doctorandos y estudiantes de todos los niveles tratan temas interdisciplinarios relativos a la cultura judeo-española.

En la Sección de Estudios Sefardíes se han llevado a cabo ya diferentes tesinas y tesis de doctorado, en tanto que otras están en vías de realización. Así, por ejemplo, una de ellas ha tratado el caso Dreyfus en la literatura en ladino; otra versa sobre las canciones humorísticas en judeo-español. 
1.2.5. Instituto Maalé Adumim para la documentación del ladino y de su cultura

Este Instituto fue creado cinco años atrás, con el patrocinio de la $\mathrm{Au}$ toridad Nacional para el Ladino. En su marco se está llevando a cabo un proyecto de recuperación y preservación de documentos antiguos en ladino. Su colección es la tercera en el mundo en lo que respecta a la cantidad de documentos que contiene. Ella comprende setenta manuscritos en ladino - entre ellos, importantes manuscritos de poesía original-, una base de datos de colecciones de folklore -incluyendo, por ejemplo, una colección de canciones (más de 2800 cassettes con testimonios de informantes), que es considerada la mayor colección de su tipo en el mundoy una recopilación de más de 6000 refranes en ladino. Estas colecciones constituyen una base de documentación valiosísima para múltiples investigaciones futuras.

\section{Marruecos}

La información que presentaré respecto del hispanismo en este país, sólo se atiene al campo de la literatura española. Debo también establecer que esta información está muy lejos de ser exhaustiva, debido a que no pude establecer un contacto adecuado con todos los centros académicos de dicho país.

Las principales universidades que, según mi conocimiento, cuentan en el marco de sus respectivas Facultades de Letras con Departamentos de Lengua y Literatura Hispánicas son: la Universidad de Mohammed VAgdal, Rabat, la Universidad de Oujda, la Universidad de Fez, la Universidad de Agadir, la Universidad de Tetuán y la Universidad de Casablanca.

En la Universidad Mohamed V de Rabat, trabaja la Profesora Oumama Aouad, catedrática de Literatura y Civilización Hispánicas en dicha universidad, quien también es responsable de la enseñanza y formación del Tercer Ciclo y Doctorado sobre Al-Andalús-Estudios Pluridisciplinares. En este marco ha dirigido numerosas tesis sobre literatura española e hispanoamericana. En relación con la literatura hispana, se destaca la tesis sobre el imaginario femenino en la poesía española actual. Entre sus investigaciones y publicaciones en el campo de la literatura española, se encuentra la de la temática del amor cortés: su origen árabe y su eco en la literatura española del siglo XVII y la aportación hispano-árabe a la literatura y cultura iberoamericana. En relación con este último 
campo de estudio, se realizan en la Universidad de Rabat diversos coloquios en torno a las huellas comunes y visiones cruzadas en los mundos árabe, ibérico e iberoamericano, cuyo coordinador es el Prof. Mohammed Salhi de dicha universidad, quien también ha coordinado un estudio y publicación sobre el siglo XVII hispano-marroquí. Entre otros campos, en la actualidad la Prof. Aouad se encuentra abocada a la investigación de la temática femenina en la literatura y en la cultura. En relación a ello, en febrero de 1999 se realizó en la universidad de Rabat un Coloquio denominado «La mujer en la transición española».

Por su parte, el Dr. Akalay Mohamed de Tánger, ha estudiado y publicado sobre la influencia de la makama árabe en el surgimiento y desarrollo del género picaresco español. Actualmente se encuentra investigando y dictando conferencias sobre las huellas de la cultura árabe en la literatura española.

El Dr. Mohamed Bouissef Rekab, de la Universidad de Tetuán, es especialista en literatura española, también investigador de la influencia del Islam y de la herencia cultural árabe en dicha literatura.

En la Universidad de Fez, Facultad de Letras, se publica semestralmente la Revista Marroquí de Estudios Hispánicos, que incluye artículos diversos sobre el hispanismo. Esta misma universidad aloja periódicamente las Jornadas Hispano-Argentino-Magrebíes de Arabismo. En el año 1998 se ha efectuado en esta universidad un Congreso Internacional Homenaje a la Generación 98, en el cual participaron hispanistas magrebíes y se trataron, entre otros, temas como Marruecos y la generación del '98. 